\title{
ANALISIS EFISIENSI EKONOMI RELATIF USAHATANI PADI SAWAH BERDASARKAN LUAS LAHAN SAWAH DI DESA SINDANGSARI, KECAMATAN BANJARSARI, KABUPATEN CIAMIS
}

\author{
REZA SITI UMAROH*, TRISNA INSAN NOOR \\ Program Studi Agribisnis Fakultas Pertanian Universitas Padjadjaran \\ Jl. Raya Bandung Sumedang KM.21, Sumedang, Jawa Barat. Telp: (022) 84288828 \\ *Email: Rezasitiumaroh@gmail.com
}

\begin{abstract}
ABSTRAK
Penelitian ini dilakukan di Kabupaten Camis, Kecamatan Banjarsari Desa Sindangsari. Kabupaten Ciamis merupakan sentral utama di Priangan Timur. Desa Sindangsari merupakan desa yang luas lahannya tidak terlalu luas. Luas lahan memiliki peran penting dalam berusahatani. Penelitian ini memiliki tujuan untuk melihat apakah ada perbedaan efisiensi antara petani yang memiliki luas lahan $\leq 0,41$ ha dan petani yang memiliki luas lahan $>0,41$ ha. Salah satu cara untuk menilai keberhasilan suatu proses produksi usahatani adalah dengan melakukan efisiensi ekonomi relatif usahatani. Untuk melihat perbedaan efisiensi relatif berdasarkan luas lahan petani padi sawah dengan menggunakan model analisis Cobb-Douglas. Dari hasil penelitian, terdapat perbedaan antara petani kecil yang mengelola lahan seluas $\leq 0,41$ ha lebih efisien dibanding dengan petani besar yang mengelola $>0,41$ ha. Hasil penelitian ini menunjukkan bahwa usahatani padi sawah di Desa Sindangsari Kecamatan Banjarsari Kabupaten Ciamis ini belum memberikan tingkat keuntungan yang maksimum kepada produsen atau petani. Skala usaha pada usahatani padi sawah di Desa Sindangsari Kecamatan Banjarsari Kabupaten Ciamis ini berada pada kondisi decreasing return to scale.
\end{abstract}

Kata kunci: Usahatani Padi Sawah, Analisis Cobb-Douglas, Efisiensi Ekonomi Relatif, Keuntungan Maksimum

\section{ABSTRACT}

The research was conduted in Kabupaten Ciamis Kecamatan Banjarsari in Sindangsari village. Kabupaten Ciamis is also central in east Priangan. The land in Sindangsari Village are not too large. Land areas of farming have an important role in agribusiness. This research have a purpose to see if there is a difference between small farmers and big farmers. One of the ways to evaluate farm level production process is by conducting farm relative economic efficiency analysis. The study want to known the difference an efficiency relative analysis based on the difference in their land by using a model Cobb-Douglas analysis. From the analysis of relative economic efficiency, apprarentry there it is proved that there is the difference between the small and big farmers. The small who cultivate the land of $\leq 0,41$ ha is more efficient than that with $>0,41$ ha. The result shows that the rice agribusiness in the studies regency hasn't given the maximum profit for the producer or farmers. Return to scale of the rice agribusiness in the research area is decreasing return to scale.

Keywords: Rice Agribusiness, Cobb-Douglas Analysis, The Efficiency of Relative Economy, Maximum Profi

\section{PENDAHULUAN}

Pertanian merupakan sektor terbesar

dalam hampir setiap ekonomi negara berkembang. Sektor ini menyediakan pangan bagi sebagian besar penduduknya, memberi lapangan pekerjaan bagi hampir seluruh angkatan kerja yang ada, menghasilkan bahan mentah bahan baku atau penolong bagi industri dan menjadi sumber terbesar bagi penerima devisa negara (Sapuan dan Silitonga, 1994).

Sampai saat ini padi masih menjadi komoditas penting dalam kebijakan pertanian di Indonesia karena terkait dengan ketahanan pangan dan swasembada beras. Dalam rangka 
sustainability swasembada beras, selain demand side pembenahan supply side dianggap masih relavan (Kusnadi, 2011).

Optimasi produktivitas padi di lahan sawah merupakan salah satu peluang peningkatan produksi padi nasional. Hal ini sangat dimungkinkan bila dikaitkan dengan hasil padi pada agroekosistem ini masih beragam antar lokasi dan belum optimal. Belum optimalnya produktivitas padi di lahan sawah, antara lain disebabkan oleh: (a) rendahnya efisiensi pemupukan, (b) belum efektifnya pengendalian hama penyakit, (c) penggunaan benih kurang bermutu dan varietas yang dipilih kurang adaptif, (d) kahat hara $\mathrm{K}$ dan unsur mikro, (e) sifat fisik tanah tidak optimal, (f) pengendalian gulma kurang optimal (Makarim et al, 2000). Mengingat besarnya peranan lahan sawah dalam menghasilkan padi, peningkatan produksi padi sawah merupakan upaya penting untuk memenuhi kebutuhan beras yang terus meningkat. Namun, akhir-akhir ini upaya tersebut semakin sulit diwujudkan. Hal tersebut tercermin dari laju pertumbuhan produksi padi sawah yang terus mengalami penurunan dari 5,51 persen per tahun selama 1973-1983, kemudian turun menjadi $2,69 \%$ per tahun selama 1983-1993, dan pada tahun 1993-2003 hanya mencapai $0,83 \%$ per tahun (Irawan et al, 2004). Dihadapkan pada kondisi produktivitas yang menurun, harga faktor produksi cenderung naik serta harga beras yang tidak menentu serta tingkat luas lahan padi sawah yang bervariasi, mendorong penelitian mengenai analisis keuntungan dan efisiensi usahatani padi sawah berdasarkan luasan lahan.
Penelitian ini bertujuan untuk mengetahui: (1) keuntungan usahatani padi sawah berlahan sempit dan luas, dan (2) efisiensi ekonomi relatif antara petani berlahan sempit dan luas di Desa Sindangsari Kecamatan Banjarsari Kabupaten Ciamis.

\section{METODE PENELITIAN}

Objek yang dikaji dalam penelitian ini adalah efisiensi ekonomi relatif usahatani padi sawah berdasarkan luas lahan sawah. Tempat penelitian dilakukan di Kabupaten Ciamis.

Jenis data yang digunakan dalam penelitian ini adalah data primer dan data sekunder. Data primer diperoleh secara langsung dari petani padi sawah yang telah ditetapkan sebagai reponden dengan alat bantu daftar pertanyaan (kuisioner). Data sekunder meliputi data penunjang dari data primer, data sekunder diperoleh dari studi literatur dari berbagai sumber, junal-jurnal, buku-buku, hasil penelitian terdahulu dan lain-lain.

Metode pengumpulan data dalam penelitian ini dengan cara survey, wawancara dan dokumentasi. Metode wawancara dilakukan dengan cara mewawancarai langsung petani responden dengan menggunakan alat bantu berupa daftar pertanyaan yang telah disusun sebelumnya serta mengadakan pengamatan (observasi) ke lapangan. Wawancara (interview) dilakukan langsung ke petani yang bersangkutan. Populasi dalam penelitian ini adalah petani yang menjadilan padi sawah sebagai komoditas utama usahataninya di Desa Sindangsari Kecamatan Banjarsari Kabupaten Ciamis yaitu sebanyak 295 orang petani padi sawah. 
Untuk menentukan jumlah sampel sebagai responden pada setiap stratum dilakukan dengan metoda proportional stratified random sampling berdasarkan data yang dilapangan yaitu sampel petani kecil dengan kriteria luas lahan padi sawah $\leq 0,41$ ha, dan sampel petani besar dengan kriteria luas lahan padi sawah $>0,41$ ha. Populasi dalam penelitian ini petani padi sawah yang berjumlah 295 orang. Jumlah anggota sampel total dientukan dengan menggunakan rumus Solvin. Formula alokasi penentuan anggota sampel secara proposional sebagai berikut:

$n=\frac{N}{1+N(e)^{2}}$

Keterangan:

$\mathrm{n} \quad$ : Jumlah Sampel

$\mathrm{N}$ : Ukuran populasi

e : batas kekeliruan (dalam penelitian ini $15 \%)$

$$
\begin{aligned}
& n=\frac{295}{1+295(0,15)^{2}} \\
& n=\frac{295}{7,64}=38,6 \approx 39
\end{aligned}
$$

Dengan menggunakan teknik Proportional Random Sampling didapatkan jumlah sampel sebanyak 38,6 jika dibulatkan menjadi 39 orang petani padi sawah.

Sebagai perbandingan, untuk menduga koefisien fungsi keuntungan dan fungsi factor share digunakan Metode Ordinary Least Squares (OLS) dan modifikasi metode kuadrat terkecil yang dikembangkan oleh Zellner (1962) yaitu Seemingly Unrelated Regression (SUR) berdasarkan pendugaan dua tahap.

Model persamaan penduga yang digunakan dalam penelitian ini adalah fungsi keuntungan UOP aktual dengan memasukkan tujuh peubah tidak tetap, dua peubah tetap dan satu peubah dummy. Model persamaannya adalah sebagai berikut:

$$
\begin{aligned}
& i n \pi_{\alpha}^{*}=\ln A^{*}+\alpha_{1}^{*} \ln W_{1}^{*}+\alpha_{2}^{*} \ln W_{2}^{*}+ \\
& \alpha_{3}^{*} \ln W_{3}^{*}+\alpha_{4}^{*} \ln W_{4}^{*}+\alpha_{5}^{*} \ln W_{5}^{*}+ \\
& \alpha_{6}^{*} \ln W_{6}^{*}+\alpha_{7}^{*} \ln W_{7}^{*}+\alpha_{8}^{*} \ln W_{8}^{*}+ \\
& \alpha_{9}^{*} \ln W_{9}^{*}+\beta_{1}^{*} \ln Z_{1}+\beta_{2}^{*} \ln Z_{2}+\lambda D+e_{0}
\end{aligned}
$$

Keterangan:

$\pi^{*} \quad=$ Keuntungan UOP atau keuntungan yang dinormalkan dengan harga output $(\mathrm{Rp} / \mathrm{kg})$

$\ln A^{*}=$ Konstanta

$W_{1}^{*}=$ Upah tenaga kerja yang dinormalkan dengan harga output (Rp/HOK)

$W_{2}^{*} \quad$ = Harga benih yang dinormalkan dengan harga output $(\mathrm{Rp} / \mathrm{kg})$

$W_{3}^{*}=$ Harga pupuk Urea yang dinormalkan dengan harga output $(\mathrm{Rp} / \mathrm{kg})$

$W_{4}^{*}=$ Harga pupuk KCLyang dinormalkan dengan harga output $(\mathrm{Rp} / \mathrm{kg})$

$W_{5}^{*} \quad=$ Harga pupuk SP-36 yang dinormalkan dengan harga output $(\mathrm{Rp} / \mathrm{kg})$

$W_{6}^{*}=$ Harga pupuk NPK yang dinormalkan dengan harga output $(\mathrm{Rp} / \mathrm{kg})$

$W_{7}^{*}=$ Harga pupuk ZA yang dinormalkan dengan harga output $(\mathrm{Rp} / \mathrm{kg})$

$W_{8}^{*}=$ Biaya pestisida yang dinormalkan dengan harga output (Rp/musim tanam)

$W_{9}^{*}=$ Biaya pupuk kandang yang dinormalkan dengan harga output (Rp/musim tanam)

$Z_{1} \quad=$ Biaya peralatan $(\mathrm{Rp} /$ musim tanam $)$

$Z_{2} \quad=$ Luas lahan (hektar/musim tanam)

$\alpha_{i}^{*}=$ Parameter input variable yang diduga, $\mathrm{i}=1,2,3,4,5$ dan 6

$\beta_{j}^{*}=$ Parameter input tetap yang diduga, $\mathrm{j}=$ 1,2

$\lambda D=$ Koefisien peubah dummy, dimana: $\mathrm{D}=1$, untuk usahatani padi sawah pada lahan luas

$\mathrm{D}=0$, untuk usahatani padi sawah pada lahan sempit

$e_{0} \quad=$ faktor kesalahan (error).

Adapun fungsi produksi Cobb-Douglas adalah sebagai berikut:

$$
\begin{aligned}
& Y=A X_{1}^{\alpha 1} X_{2}^{\alpha 2} X_{3}^{\alpha 3} X_{4}^{\alpha 4} X_{5}^{\alpha 5} X_{6}^{\alpha 6} X_{7}^{\alpha 7} \\
& X_{8}^{\alpha 8} X_{9}^{\alpha 9} Z_{1}^{\beta 1} Z_{2}^{\beta 2}
\end{aligned}
$$




$$
Y=A\left(\sum_{i=1}^{4} X i^{\alpha i} \sum_{j=1}^{1} Z j^{\beta j}\right)
$$

Dimana:

$$
\begin{array}{ll}
\mathrm{Y} & \text { : Produksi padi sawah } \\
\mathrm{X}_{1} & \text { : Tenaga Kerja } \\
\mathrm{X}_{2} & \text { : Benih } \\
\mathrm{X}_{3} & \text { : pupuk urea } \\
\mathrm{X}_{4} & \text { : pupuk kcl } \\
\mathrm{X}_{5} & \text { : pupuk SP-36 } \\
\mathrm{X}_{6} & \text { : pupuk NPK } \\
\mathrm{X}_{7} & \text { : pupuk ZA } \\
\mathrm{X}_{8} & \text { : pestisida } \\
\mathrm{X}_{9} & \text { : pupuk kandang } \\
\mathrm{Z}_{1} & \text { : Peralatan } \\
\mathrm{Z}_{2} & \text { : Luas lahan } \\
\alpha i & \text { : koefisien input variabel i } \\
\beta j & \text { : koefisien input tetap j }
\end{array}
$$

Fungsi keuntungan Cobb-Douglas dipergunakan untuk mengetahui hubungan antara input dan output serta mengukur pengaruh dari berbagai perubahan harga dari input terhadap produksi. Perkembangan terakhir adalah menurunkan fungsi keuntungan Cobb-douglas dengan teknik "Unit Output Price" atau UOP of Cobb-Douglas Profit

Function, yaitu suatu fungsi yang melibatkan harga produksi dan produksi yang telah dinormalkan dengan harga tertentu yang disebut "Normalized Profit Function".

Untuk menjawab tujuan penelitian yang pertama apakah keuntungan maksimum jangka pendek sudah tercapai, maka analisis yang dilakukan adalah dengan cara melakukan pembandingan parameter masing-masing input tidak tetap $\left(\alpha_{i}^{*}\right)$ dari fungsi keuntungan dengan parameter masing-masing input tidak tetap $\left(\alpha_{i}{ }^{*}\right.$ ") dari fungsi permintaan atau faktor sharenya. Untuk menjawab tujuan keduanya yaitu diperlukannya ekonomi skala usahatani padi sawah di daerah penelitian, maka dilakukan pengujian apakah usahatani padi sawah yang diteliti berada pada kondisi kenaikan hasil yang meningkat, menurun atau bahkan tetap. Pengujian hipotesis dirumuskan sebagai berikut:

$\mathrm{H}_{0}=\left(\sum_{i=1}^{n} \beta_{i}^{*}\right) \quad=1$ (constant return to scale)

$\mathrm{H}_{1} \quad=\left(\sum_{i=1}^{n} \beta_{i}^{*}\right) \quad<1$ (decreasing return to scale.

Perbedaan efisiensi ekonomi relatif antara usahatani padi sawah pada lahan luas dan lahan sempit dilakukan pengujian, model fungsi keuntungan UOP actual gabungan dapat dirumuskan sebagai berikut:

$\ln \pi_{\alpha}=\ln A^{*}+\sum_{i=1}^{6} \alpha_{i}^{*} \ln W_{i}^{*}+$ $\sum_{i=1}^{2} \beta_{j}^{*} \ln Z_{j}+\lambda D$

$\mathrm{D}=1$ untuk petani berlahan luas dan

$\mathrm{D}=0$ untuk petani berlahan sempit.

Pengujian hipotesis adannya perbedaan efisiensi teknik relatif dalam penelitian ini adalah sebagai berikut:

- $\mathrm{H}_{0}: \lambda D=0$

Tidak ada perbedaan efisiensi teknik relatif antara usahatani padi sawah di lahan luas dan lahan sempit.

- $\mathrm{H}_{1}: \lambda D \neq 0$

Ada perbedaan efisiensi teknik relatif antara usahatani padi sawah di lahan luas dan sempit.

\section{HASIL DAN PEMBAHASAN}

\section{Keadaan Umum Lokasi Penelitian}

Geografis wilayah Kabupaten Ciamis berada pada $108^{\circ} 19^{\prime}$ sampai dengan $108^{\circ} 43^{\prime}$ Bujur Timur dan 703'39" Lintang Selatan. Kecamatan paling utara adalah Kecamatan Sukamantri berada pada titik 7,083 garis lintang 
selatan, kecamatan paling barat adalah Kecamatan Cihaurbeuti dengan titik 108,303 bujur timur, kecamatan paling timur adalah Kecamatan Lakbok dengan titik 108,683 bujur timur. Luas wilayan Kabupaten Ciamis secara keseluruhan mencapai 143,387 Ha.

Desa Sindangsari dengan luas wilayah 354,30 Hektar terdiri dari 3 (tiga) wilayah Dusun, yaitu Dusun Sindanglaya, Dusun Kedungkendal dan Dusun Pahauran. Desa ini terdapat 7 RW dan 29 RT dengan jumlah penduduk 8.583 jiwa, terdiri jumlah Laki-laki 4.332 dan jumlah perempuan 4.251 jiwa dengan jumlah Kepala Keluarga 2.649. Luas wilayah Desa Sindangsari terbagi menjadi tiga yaitu tanah sawah seluas 131 Hektar, tanah darat seluas 220,30 Hektar adalah wilayah hutan milik masyarakat.

Masyarakat Desa Sindangsari pada umumnya berpendidikan SD, namun ada juga yang lulusan SMP, SMA, Perguruan Tinggi atau S1 (Strata 1) bahkan juga ada yang menyandang pendidikan hingga S2 (Strata 2) akan tetapi jumlahnya relatif kecil. Mata pencaharian masyarakat di Desa Sindangsari sekitar 90\% adalah Petani, $7.5 \%$ buruh tani dan pedagang dan $2.5 \%$ adalah PNS.

\section{Karakteristik Responden}

Tingkat pendidikan petani padi sawah di Desa Sindangsari beragam. Mulai dari petani yang tamat SD, tamat SLTP, tamat SLTA dan taman perguruan tinggi. Melihat pada tabel bahwa pendidikan terbesar hanya tamat sampai dengan sekolah dasar yaitu sebanyak 66\% maka pengelolaan usahatani padi sawah lebih banyak hanya menitikberatkan pada kemampuan teknis yang diperoleh secara turun temurun. Petani padi sawah umumnya tidak mendapatkan pendidikan khusus dalam berusahatani, pengetahuan petani hanya diperoleh dari pengalaman yang turun temurun sehingga dengan berbekal pengalaman tersebut dapat melakukan usahatani padi sawah dengan baik.

Petani padi sawah mempunyai pengalaman yang bervariasi dalam usahatani padi sawah, sebagian besar petani mempunyai pengalaman dalam usahatani padi sawah di atas dua puluh tahun, hal ini merupakan petani tradisional yang mampu mengelola faktorfaktor produksi.

Luas lahan petani pada penelitian ini dibagi menjadi dua katagori, yaitu sampel petani kecil dengan kriteria luas lahan padi sawah $\leq 0,41$ ha dan sampel petani besar dengan kriteria luas lahan padi sawah $>0,41$ ha. Sebanyak 59\% merupakan petani kecil dengan kriteria luas lahan padi sawah sebesar $\leq 0,41$ ha, dan sebanyak $41 \%$ petani Desa Sindangsari merupakan petani besar dengan luas lahan padi sawah $>0,41$ ha.

\section{Analisis Penggunaan Faktor-Faktor Produksi}

\section{Tenaga Kerja}

Tenaga kerja merupakan faktor produksi yang cukup penting dan harus diperhitungkan dalam proses produksi baik dari segi jumlahnya, kualitas tenaga kerja dan macam tenaga tenaga kerja itu sendiri. Pada petani kecil penggunaan tenagakerja mengutamakan dalam keluarga sedangkan tenaga kerja dari petani besar berasal dari dalam keluarga dan tetangga sekitar. 


\section{Benih, Pupuk dan Pestisida}

Banyaknya kebutuhan setiap saprotan berbeda-beda. Hal ini disebabkan oleh kegunaan dan manfaat dari pupuk dan pestisida memiliki peranan yang berbeda. Pupuk kandang memiliki volume terbanyak dari pupuk yang lainnya yaitu sebanyak $4305 \mathrm{~kg}$. Perbedaan input dari petani kecil dan petani besar lumayan jauh berbeda, hal ini bisa dikarenakan perbedaan lahan yang mengakibatkan perbedaan jumlah input yang dibutuhkan. Benih yang dibutuhkan untuk seluruhnya adalah sebanyak $642 \mathrm{~kg}$ per ha dengan varietas benih Ciherang yang merupakan benih lokal. Benih ini dijual curah per kg dan ada yang dijual langsung per $5 \mathrm{~kg}$ ber bungkusnya. Untuk harga curah per kg yaitu Rp 12.000 dan Rp 65.000 per 5 kg. Petani kecil membutuhkan benih sebanyak $226 \mathrm{~kg}$ per ha dalam satu musim sedangkan petani besar membutuhkan benih sebanyak $416 \mathrm{~kg}$ per ha dalam satu musim.

\section{Lahan dan Peralatan}

Petani kecil rata-rata menguasai lahan seluas 0,235 ha dan petani besar rata-rata lahan yang diusahakan seluas 0,668 ha, sedangkan rata-rata luas lahan dari keseluruhan responden adalah 0,413 ha. Luas lahan yang diusahakan oleh 39 petani adalah 16,09 ha yang terdiri atas petani kecil dengan jumlah responden 23 mengolah lahan 5,42 ha dan petani besar dengan jumlah responden 16 mengolah lahan 10,68 ha.

Peralatan yang dipergunakan dalam usahatani padi sawah tidak selalu diadakan setiap musim tanam akan tetapi penggunaan alat-alat pertanian mempunyai umur pakai antara 5 sampai 10 tahun yang dipergunakan secara komplek atas kebutuhan petani. Adapun peralatan yang dibutuhkan petani yaitu cangkul, sprayer, arit, traktor, ember dan lain-lain. Dari uraian tersebut dapat dikategorikan bahwa faktor luas lahan dan peralatan sebagai input tetap dalam suatu proses produksi

\section{Pengujian Keuntungan Maksimum Jangka Pendek}

Pengujian keuntungan maksimum jangka pendek ini bertujuan untuk mengetahui apakah usahatani padi sawah yang ada di Desa Sindangsari Kecamatan Banjarsari Kabupaten Ciamis ini telah mencapai keuntungan maksimum atau belum mencapai keuntungan maksimum (Tabel 1).

Berdasarkan Tabel 1 dapat diketahui bahwa pengujian serentak keuntungan maksimum menunjukan hipotesis nol menyatakan $\alpha_{i}^{*}=\alpha_{i}^{* "}(i=1,2,3 \ldots 9)$ diterima pada derajat kesalahan $\alpha=0,05$ (P-Value 0,591 ) yang artinya bahwa usahatani padi sawah dapat mencapai keuntungan maksimum. Dengan kata lain beberapa input-input variabel sudah optimal. Dari hasil pengujian parsial tampak bahwa dari masing-masing input variabel pupuk $\mathrm{KCl}$ dan pupuk SP-36, hipotesis nol ditolak pada derajat kesalahan $\alpha=0,05$, yang artinya alokasi penggunaan pupuk $\mathrm{KCl}$ dan pupuk SP-36 tidak ada yang optimal. Hal ini menunjukan bahwa biaya marjinal (Marjinal Cost/MC) dari pupuk $\mathrm{KCl}$ dan pupuk SP-36 tersebut belum sama dengan penerimaan marginalnya (Marginal Revenue/MR) sehingga keuntungan maksimal tidak dapat tercapai. Sedangkan pengujian alokasi input variabel 
lainnya diterima pada derajat $\alpha=0,05$ yang artinya alokasi penggunaan input variabel pupuk ZA, pestisida dan pupuk kandang telah mencapai optimum.

tenaga kerja, benih, pupuk urea, pupuk NPK,

Tabel 1. Pengujian Keuntungan Maksimum Jangka Pendek pada Usahatani Padi Sawah di Desa Sindangsari, 2018

\begin{tabular}{|c|c|c|c|}
\hline Hipotesis nol & Hipotesis alternatif & Pengujian & Keputusan \\
\hline$\alpha_{i}^{*}=\alpha_{i}^{* "}$ & $\alpha_{i}^{*} \neq \alpha_{i}^{* "}$ & Keuntungan Maksimum Serentak & $\begin{array}{l}\text { Terima } \mathrm{H}_{0} \\
\text { (P: } 0.591)\end{array}$ \\
\hline$\alpha_{1}^{*}=\alpha_{1}^{* "}$ & $\alpha_{1}^{*} \neq \alpha_{1}^{* "}$ & Alokasi optimum tenaga kerja & $\begin{array}{l}\text { Terima } \mathrm{H}_{0} \\
(\mathrm{P}: 0.434)\end{array}$ \\
\hline$\alpha_{2}^{*}=\alpha_{2}^{* "}$ & $\alpha_{2}^{*} \neq \alpha_{2}^{* "}$ & Alokasi optimum benih & $\begin{array}{l}\text { Terima } \mathrm{H}_{0} \\
(\mathrm{P}: 0.157)\end{array}$ \\
\hline$\alpha_{3}^{*}=\alpha_{3}^{* "}$ & $\alpha_{3}^{*} \neq \alpha_{3}^{* "}$ & Alokasi optimum urea & $\begin{array}{l}\text { Terima } \mathrm{H}_{0} \\
(\mathrm{P}: 0.363)\end{array}$ \\
\hline$\alpha_{4}^{*}=\alpha_{4}^{* "}$ & $\alpha_{4}^{*} \neq \alpha_{4}^{* "}$ & Alokasi optimum KCL & $\begin{array}{c}\text { Tolak } \mathrm{H}_{0} \\
\text { (P: } 0.001)\end{array}$ \\
\hline$\alpha_{5}^{*}=\alpha_{5}^{* "}$ & $\alpha_{5}^{*} \neq \alpha_{5}^{* "}$ & Alokasi optimum SP-36 & $\begin{array}{l}\text { Tolak } \mathrm{H}_{0} \\
\text { (P: } 0.037)\end{array}$ \\
\hline$\alpha_{6}^{*}=\alpha_{6}^{* "}$ & $\alpha_{6}^{*} \neq \alpha_{6}^{* "}$ & Alokasi optimum NPK & $\begin{array}{l}\text { Terima } \mathrm{H}_{0} \\
\text { (P: } 0.418)\end{array}$ \\
\hline$\alpha_{7}^{*}=\alpha_{7}^{* "}$ & $\alpha_{7}^{*} \neq \alpha_{7}^{* "}$ & Alokasi optimum ZA & $\begin{array}{l}\text { Terima } \mathrm{H}_{0} \\
(\mathrm{P}: 0.961)\end{array}$ \\
\hline$\alpha_{8}^{*}=\alpha_{8}^{* "}$ & $\alpha_{8}^{*} \neq \alpha_{8}^{* "}$ & Alokasi optimum pestisida & $\begin{array}{l}\text { Terima } \mathrm{H}_{0} \\
(\mathrm{P}: 0.172)\end{array}$ \\
\hline$\alpha_{9}^{*}=\alpha_{9}^{* "}$ & $\alpha_{9}^{*} \neq \alpha_{9}^{* "}$ & Alokasi optimum pupuk kandang & $\begin{array}{l}\text { Terima } \mathrm{H}_{0} \\
\text { (P: } 0.668)\end{array}$ \\
\hline
\end{tabular}

Sumber: Data diolah, 2018

\section{Pengujian Skala Usaha}

Skala usaha pada usahatani padi sawah di

\section{Desa Sindangsari Kecamatan Banjarsari}

Kabupaten Ciamis ini tidak berada pada kondisi constant returns to scale. Dilihat dari nilai dugaan $\sum_{j=1}^{9} \beta j^{*}=0,2333$ menunjukkan bahwa kondisi skala usaha produksi pada usahatani padi sawah berada pada keadaan decreasing return to scale karena nilai return to scale kurang dari 1. Decreasing return to scale

Tabel 2. Pendugaan Parameter Pengujian Tingkat Skala Usaha pada Usahatani Padi Sawah di Desa Sindangsari

\begin{tabular}{cccc}
\hline Nilai Dugaan & Hipotesis & F-Hitung & Keputusan \\
\hline \multirow{2}{*}{0,2333} & $\mathrm{H}_{0}: \beta_{1}^{*}+\beta_{2}^{*}=1$ & \multirow{2}{*}{34,069} & Tolak $\mathrm{H}_{0}$ \\
& $\mathrm{H}_{1}: \beta_{1}^{*}+\beta_{2}^{*} \neq 1$ & & 0,001 \\
\hline
\end{tabular}

Sumber: Data diolah, 2018 tidak mencapai titik maksimum penyebabnya keuntungan tidak tercapai. Periode optimum ini terjadi karena keuntungan maksimum dam kondisi maksimal sudah melampaui batas atau sudah terlewati. Sehingga input apapun yang dimasuki atau diberikan tidak akan meningkatkan produksi dan pendapatan bahkan akan mengalami kondisi jenuh sehingga penggunaan input menurun. 


\section{Pengujian Efisiensi Ekonomi Relatif}

Dari pendugaan fungsi keuntungan UOP pada Tabel 3 yang dimodifikasi dengan variabel dummy dapat diketahui efisiensi ekonomi relatif atau petani mana yang mempunyai efisiensi ekonomi paling tinggi. Dalam Tabel 3 model II, diketahui besarnya parameter variabel dummy untuk petani besar $\left(\delta^{M}\right)$ yaitu $-0,1761$ sehingga dummy untuk petani besar bertanda negatif dan nyata terhadap keuntungan usahatani, yang mempunyai makna bahwa efisiensi petani besar berada lebih kecil dibandingkan petani kecil atau dengan kata lain bahwa usahatani padi sawah pada petani kecil lebih efisien dibandingkan dengan petani besar. Tabel 3. Pendugaan Parameter Pengujian Tingkat Skala Usaha pada Usahatani Padi Sawah di Desa Sindangsari

\begin{tabular}{lccc}
\hline \multirow{2}{*}{ Variabel } & \multirow{2}{*}{ Parameter } & \multicolumn{2}{c}{$\begin{array}{c}\text { Koefisien Regresi } \\
\text { Model }\end{array}$} \\
\cline { 3 - 4 } & & I & II \\
\hline \multirow{2}{*}{ Konstanta } & \multirow{2}{*}{$\mathrm{A}^{*}$} & $\begin{array}{r}-5,519 \\
(0,217)\end{array}$ & $\begin{array}{r}-5,5191 \\
(0,121)\end{array}$ \\
\hline \multirow{2}{*}{$\mathrm{DM}$} & \multirow{2}{*}{$\delta^{M}$} & $\begin{array}{r}-0,176 \\
(0,085)\end{array}$ & $\begin{array}{c}-0,1761 \\
(0,028)\end{array}$ \\
\hline
\end{tabular}

Sumber: Data diolah, 2018

\section{PENUTUP}

Hasil pendugaan fungsi keuntungan UOP usahatani padi sawah menunjukkan bahwa satu input tetap yaitu luas lahan dan tujuh input variabel yang terdiri dari tenaga kerja, benih, pupuk urea, pupuk $\mathrm{KCl}$, pupuk NPK, pupuk ZA dan pupuk kandang mempunyai hubungan positif terhadap keuntungan usaha yang berarti kenaikan input tetap akan menaikan keuntungan. Selain itu, terdapat satu input tetap yaitu biaya peralatan dan dua input variabel yang terdiri atas pupuk SP-36 dan pestisida mempunyai hubungan negatif terhadap keuntungan usahatani.

Hasil penelitian ini menunjukkan bahwa usahatani padi sawah di Desa Sindangsari Kecamatan Banjarsari Kabupaten Ciamis ini belum memberikan tingkat keuntungan yang maksimum kepada produsen atau petani. Namun jika dilihat dari penggunaan input variabel menunjukkan bahwa pupuk $\mathrm{KCl}$ dan pupuk SP-36 yang belum optimal. Sedangkan pengalokasian input variabel tenaga kerja, benih, pupuk urea, pupuk NPK, pupuk ZA, pestisida dan pupuk kandang telah mencapai optimum.

Dari kesembilan input tidak tetap tersebut yang nyata mempengaruhi keuntungan usahatani adalah tenagakerja, pupuk SP-36, pupuk ZA, pestisida dengan derajat kepercayaan 95\%, Sedangkan input tidak tetap yang tidak berpengaruh nyata tergadap keuntungan usahatani adalah benih, pupuk urea, pupuk KCl, pupuk NPK, pupuk kandang dengan tingkat kepercayaan $95 \%$.

Skala usaha pada usahatani padi sawah di Desa Sindangsari Kecamatan Banjarsari Kabupaten Ciamis ini berada pada kondisi decreasing return to scale karena nilai return to scale kurang dari 1.

Dari hasil analisis efesiensi ekonomi relatif antara kedua kategori berdasarkan skala luas lahan yaitu skala luas lahan 
dibawah 0,41 hektar (petani kecil) dan skala luas lahan lebih dari diatas 0,41 hektar dapat dibuktikan terdapat perbedaan tingkat efisiensi dimana petani kecil lebih efisien dibandingkan petani besar.

\section{UCAPAN TERIMA KASIH}

Dalam penyusunan jurnal ini, tidak terlaksana tanpa bantuan, dorongan, bimbingan dan petunjuk dari berbagai pihak. Penulis mengucapkan terima kasih kepada dosen pembimbing, orang tua dan teman-teman yang sudah membantu penulis dalam menulis jurnal ini.

\section{DAFTAR PUSTAKA}

Budiono. 1992. Teori pertumbuhan Ekonomi. Yogyakarta, BPFE UGM.

Gustiyana, H. 2004. Analisis Pendapatan Usahatani untuk Produk Pertanian. Salemba empat: Jakarta.

Irawan B, Winarso B, Sodikin I, Gatoet SH. 2004. Analisis Faktor Penyebab Perlambatan Produksi Komoditas Pangan Utama. Pusat Penelitian dan Pengembangan Sosial Ekonomi Pertanian.

Juwandi. 2003. Analisis Keuntungan, Skala Usaha dan Efisiensi Ekonomi Relatif Usaha Peternakan Ayam Petelur di Kabupaten Kendal. Tesis. Program Pascasarjana. Universitas Diponegero. Semarang.

Kusnadi, N, dkk. 2011. Analisis Efisiensi Usahatani Padi di Beberapa Sentra Produksi Padi di Indonesia. Jurnal Agro Ekonomi, Volume 29 No. 1. Mei 2011.

Lau, L. J., and P. A. Yotopaulus. 1971. A Test for Realtive Efficiency and Application to Indian Agriculture. American Economic Review.
Lau, L. J., and P. A. Yotopaulus. 1972. Profit, Supply, and Factor Demand Function. Am. J. Agr. Econ. 54: 1118.

Makarim, A.K., S. Abdurrachman, dan S. Purba. 2000. Efisiensi input produksi tanaman pangan melalui prescription farming. Dalam. Makarim, et al. (Eds). Tonggak Kemajuan Teknologi Tanaman Pangan. Konsep dan Strategi Peningkatan Produksi Pangan. Pusat Penelitian dan Pengembangan Tanaman Pangan, Bogor.

Mubyarto. 1989. Pengantar Ekonomi Pertanian. Jakarta: Edisi ke-tiga, LP3S.

Sapuan., dan S, Chrisman, 1994. Prosiding Seminar Pembangunan Pertanian Dalam Menanggulangi Kemiskinan, PERHEPI (Perhimpunan Ekonomi Pertanian).

Soekartawi. 1993. Prinsip Dasar Ekonomi Pertanian - Teori dan Aplikasi. PT. Raja Grafindo. Jakarta.

Soekartawi. 2003. Analisis Usaha Tani. UI Press. Jakarta.

Soekartawi. 2006. Teori Ekonomi Produksi, Dengan Pokok Bahasan Analisis Fungsi Cobb-Douglas. PT. Raja Grafindo Persada. Jakarta.

Sudarsono. 1994. Hukum Waris dan Sistem Bilateral. Jakarta: Rineka Cipta.

Sumbodo, B. T. 1996. Analisis Efisiensi Ekonomi Relatif Usahatani Kopi Rakyat di Timor Timur. Tesis. Institut Pertanian Bogor. Bogor.

Yotopoulos, Pan, A and Nugent, Jeffrey B. 1976. Economics of Development (Empirical Investigations) Harper International Edition. Harper \& Row Publishers. New York. 